\title{
Characterization of Poly-Silicon Film Prepared by Excimer Laser Annealing
}

\author{
Naoto MATSUO, Yoichiro AYA*, Takeshi KANAMORI, Tomoyuki NOUDA*, \\ Hiroki HAMADA*, Akinori KINUGASA and Tadaki MIYOSHI \\ Department of Electrical \& Electronic Engineering, Yamaguchi University, \\ Tokiwadai, Ube 755-8611, Japan \\ *Microelectronics Research Center, SANYO Electric Co., Ltd., \\ 180, Ohmori, Anpachi-Cho, Anpachi-Gun, Gifu 503-0116, Japan.
}

(Received March 16, 1998, Accepted July 4, 1998)

Characteristics of polycrystalline silicon (poly-Si) film prepared by excimer laser annealing was examined. The crystallinity increases as increasing the laser energy density and the number of shot. The secondary grain growth occurs at the laser energy density and the number of shot larger than the critical values. The crystallinity of the poly-Si with dehydrogenation prior to the laser irradiation is better than that with non-dehydrogenation. Its surface roughness becomes same as or better than that with non-dehydrogenation.

\section{Introduction}

Low-temperature processed polycrystalline silicon (poly-Si) film is attractive for thin-film transistors (TFTs) of active-matrix liquid-crystal displays $(\mathrm{AMLCDs})^{1)}$. The characteristics of the poly-Si film prepared by excimer laser annealing (ELA) or solid phase crystallization (SPC) ${ }^{2-4)}$ and that of the TFTs on the poly-Si prepared by SPC $^{5,6}$ have been reported. For the crystal growth mechanism, the rapid solidification of $\mathrm{Si}$ was reported from the view point of crystallization through the bulk nucleation directly from the super cooled liquid ${ }^{7,8)}$. The purpose of this paper is to examine both the crystallinity and the surface morphology of the poly-Si film prepared by the ELA considering the laser energy density, the number of the laser shot and the dehydrogenation.

\section{Experimental}

Table 1 shows the deposited condition of amorphous-silicon (a-Si). An a-Si film is deposited on the quartz substrate by low pressure chemical vapour deposition (LPCVD) using $\mathrm{Si}_{2} \mathrm{H}_{6}$. The a-Si thickness is 50 or $70 \mathrm{~nm}$. Prior to laser irradiation, some wafers with the a-Si are dehydrogenated by annealing in the vacuum chamber. Table 2 shows the condition of the ELA. The a-Si is recrystallized by $\mathrm{KrF}$ excimer laser pulses at room temperature.
Table 1 Deposited condition of a-Si

\begin{tabular}{c|c|c|c}
\hline \hline Sample & A & B & C \\
\hline Method & \multicolumn{3}{|c}{ LPCVD } \\
\hline Gas & \multicolumn{3}{|c}{ Si2H6 } \\
\hline Temperature & \multicolumn{3}{|c}{$450^{\circ} \mathrm{C}$} \\
\hline Thickness & $70 \mathrm{~nm}$ & $70 \mathrm{~nm}$ & $50 \mathrm{~nm}$ \\
\hline
\end{tabular}

Table 2 Condition of the ELA

\begin{tabular}{|c|c|c|c|}
\hline Sample & A & B & $\mathrm{C}$ \\
\hline Laser & \multicolumn{3}{|c|}{$\mathrm{KrF}$} \\
\hline Energy Density & \multicolumn{2}{|c|}{$175 \sim 250 \mathrm{~mJ} / \mathrm{cm}^{2}$} & $175 \sim 225 \mathrm{~mJ} / \mathrm{cm}^{2}$ \\
\hline Number of Shot & \multicolumn{3}{|c|}{$8 \sim 200$ shots } \\
\hline Temperature & \multicolumn{3}{|c|}{ RT } \\
\hline Dehydrogenation & & $550^{\circ} \mathrm{C}, 1 \mathrm{~h}$ & \\
\hline
\end{tabular}

The energy densities of the laser are from 175 to $250 \mathrm{~mJ} / \mathrm{cm}^{2}$. The numbers of shot are from 8 to 200. The characteristics of the poly-Si is evaluated by the Raman spectroscopy, electron spin resonance (ESR), scanning electron microscopy (SEM) and atomic force microscopy (AFM). 


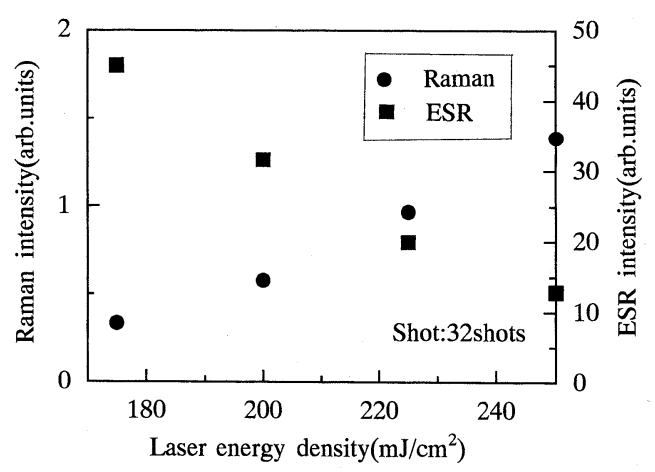

Fig. 1 Relationships both between the Raman intensity and the laser energy density and between the ESR intensity and the laser energy density at 32 shots. The film thickness is $70 \mathrm{~nm}$.

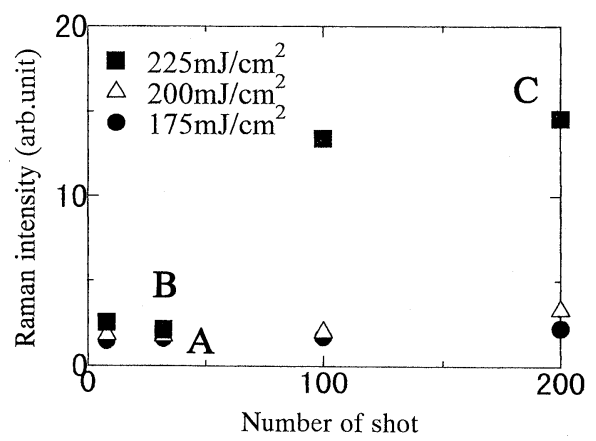

Fig. 2 Relationship between the Raman intensity and the number of shot. The film thickness is 50 nm.

\section{Results and discussion}

Figure 1 shows the relationships both between the Raman peak intensity and the laser energy density and between the ESR intensity and the laser energy density at 32 shots. The film thickness is 70 $\mathrm{nm}$. The Raman peak intensity increases and the ESR intensity decreases as the laser energy density becomes large. It is found that the crystallinity increases as the laser energy density becomes large.

Although the peak shift for $200 \sim 225 \mathrm{~mJ} / \mathrm{cm}^{2}$ is $512 \mathrm{~cm}^{-1}$ which corresponds to the Si single crystal, that for $175 \mathrm{~mJ} / \mathrm{cm}^{2}$ is not necessarily equl to $512 \mathrm{~cm}^{-1}$. This is because a-Si area remains after laser irradiation. Figure 2 shows the relationship between the Raman intensity and the number of shot at the laser energy density of $175 \sim 225 \mathrm{~mJ} / \mathrm{cm}^{2}$. The film thickness is $50 \mathrm{~nm}$. It is found that the laser energy density and the number of shot larger

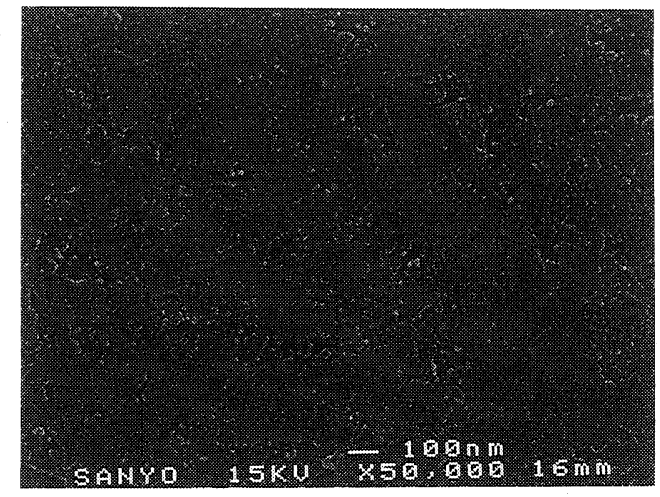

(a)

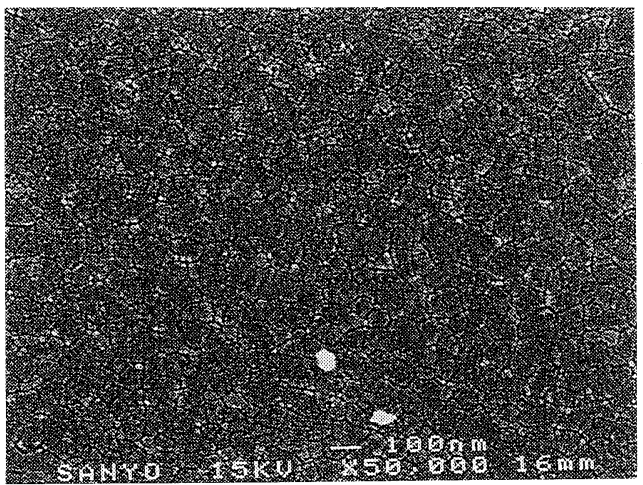

(b)

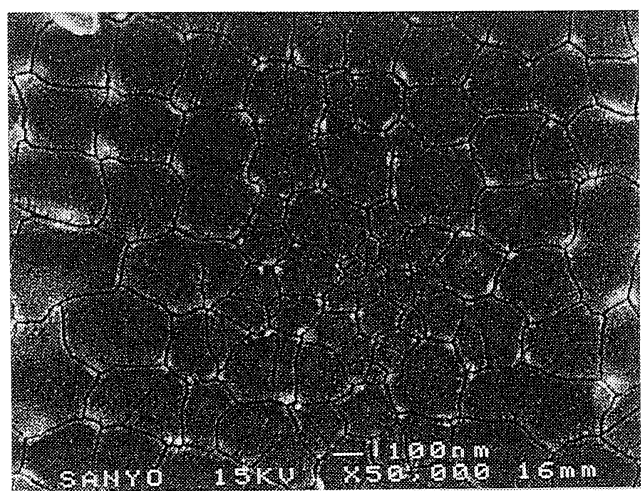

(c)

Fig. 3 SEM photographs for the condition of 200 $\mathrm{mJ} / \mathrm{cm}^{2}, 32$ shots (a), $225 \mathrm{~mJ} / \mathrm{cm}^{2}, 32$ shots (b) and $225 \mathrm{~mJ} / \mathrm{cm}^{2}, 200$ shots (c).

than critical values are needed to realize a good crystallinity. The differences of Raman intensities at the laser energy density of $175 \sim 225 \mathrm{~mJ} / \mathrm{cm}^{2}$ and 32 shots become small comparing with Fig. 1. The reason of this is thought to be due to the difference of the film thickness between the sample of 


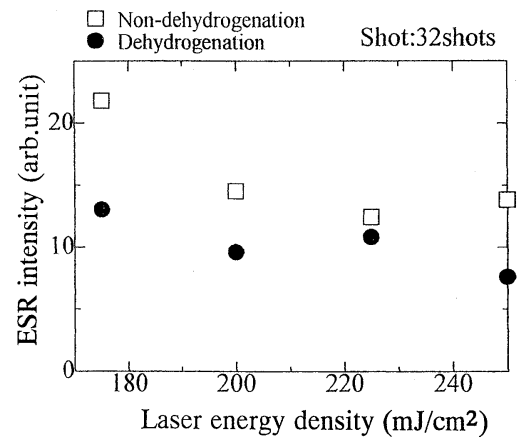

Fig. 4 Relationship between the ESR intensity and the laser energy density for the both conditions with dehydrogenation and with non-dehydrogenation. The film thickness is $70 \mathrm{~nm}$.

Fig. 1 and that of Fig. 2: The dependence of the crystallinity on the laser energy density becomes remarkable for the large film thickness. Figure 3(a), (b) and (c) show the SEM photographs for the condition of $200 \mathrm{~mJ} / \mathrm{cm}^{2}, 32$ shots (A), $225 \mathrm{~mJ} / \mathrm{cm}^{2}$, 32 shots (B) and $225 \mathrm{~mJ} / \mathrm{cm}^{2}, 200$ shots (C). The amorphous parts are observed for $\mathrm{A}$ and the recrystallized grains are observed for $\mathrm{B}$. The area of the amorphous parts becomes small as increasing the number of shots, and the grain size is constant during this stage. From this result, it is thought that the condition of A corresponds to the nucleation-stage and that of $\mathrm{B}$ corresponds to the grain-growth stage. The grain sizes for $\mathrm{B}$ and $\mathrm{C}$ are $50 \sim 100 \mathrm{~nm}$ and $200 \sim 300 \mathrm{~nm}$, respectively. From the relationship between the grain size and the film thickness, it is found that the textured growth occurs at $\mathrm{B}$, and the secondary grain growth occurs at C. It is thought that the secondary grain growth occurs at the laser energy density and the number of shot larger than the critical values. It is important to consider the effect of the number of shot as well as that of the energy density for the recrysttalization mechanism under the pulse laser irradiation. This phenomenon will be explained by the model that the Si-atoms jump the grain boundary by getting the thermal energy from the laser'). One example of the model that the secondary growth occurs at the critical conditions of both the laser energy density and the number of laser shots is as follows: The activation energy, Qa, of the jump for $\mathrm{Si}$ atoms at the grain boundary changes under the critical conditions. Because the number of the Siatoms which jump from one grain to the neighboring grain is proportional to $\exp (\sim \mathrm{Qa} / \mathrm{kT})$, the rapid increase of the grain size occurs ${ }^{10)}$.

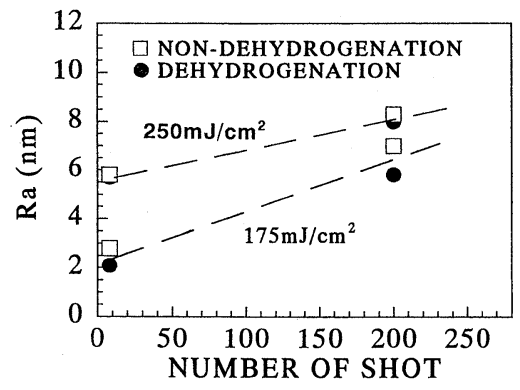

Fig. 5 Relationship between the $\mathrm{Ra}$ of the poly-Si surface and the number of shot at $175 \mathrm{~mJ} / \mathrm{cm}^{2}$ and $250 \mathrm{~mJ} / \mathrm{cm}^{2}$. The film thickness is $70 \mathrm{~nm}$.

Next, the influence of the dehydrogenation on the crystallinity is discussed. Figure $\mathbf{4}$ shows the relationship between the ESR intensity and the laser energy density for the both conditions with dehydrogenation and with non-dehydrogenation. The crystallinity of the poly-Si with dehydrogenation is better than that with non-dehydrogenation. From this result, it is thought that the annealing in the vacuum chamber prior to the laser irradiation removes the hydrogen molecules in the a-Si and accelerates the nucleation. The effect of the thermal annealing on the crystallinity is thought to be negligible for the present condition ${ }^{4}$. The ESR intensity at $250 \mathrm{~mJ} / \mathrm{cm}^{2}$ is different from that in Fig. 1. It is thought that this is due to the fluctuation of the crystallinity at the large energy density such as $250 \mathrm{~mJ} / \mathrm{cm}^{2}$. Figure 5 shows the relationship between the mean roughness $(\mathrm{Ra})$ of the poly-Si surface and the number of shot at $175 \mathrm{~mJ} / \mathrm{cm}^{2}$ and $250 \mathrm{~mJ} / \mathrm{cm}^{2}$. Ra of the poly-Si with dehydrogenation becomes smaller than that with non-dehydrogenation at $175 \mathrm{~mJ} / \mathrm{cm}^{2}$. The hydrogens including in the a-Si make the surface roughly during the first laser irradiation for non-dehydrogenation, because they go out of the a-Si abruptly during the irradiation. $\mathrm{Ra}$ of the poly-Si with dehydrogenation becomes same as that with non-dehydrogenation at $250 \mathrm{~mJ} / \mathrm{cm}^{2}$. The effect of dehydrogenation on $\mathrm{Ra}$ is covered, because the surface roughness made by the laser irradiation becomes large at $250 \mathrm{~mJ} / \mathrm{cm}^{2}$. $\mathrm{Ra}$ increases with increasing the number of shot and laser energy density. It is thought that because the difference of the height between the grains becomes large as the grain grows, $\mathrm{Ra}$ becomes large as increasing the laser energy density and the number of shots. The reason why the crystallinity and the surface roughness of the film at the condition of the dehydrogenation becomes better than those 
at the non-dehydrogenation is thought to be due to the acceleration of the nucleation and growth which is generated by the dehydrogenation.

\section{Conclusions}

Characteristics of poly-Si film prepared by ELA method was examined. First, the crystallinity of the poly-Si film increases as the laser energy density and the number of shots become large. The secondary grain growth occurs at the laser energy density and the number of shots larger than the critical values. It is important to consider the effect of the number of shots as well as that of the energy density for the recrystallization mechanism under the pulse laser irradiation. Secondly, the crystallinity of the poly-Si with dehydrogenation is better than that with non-dehydrogenation. The surface roughness of the poly-Si with dehydrogenation becomes same as or better than that with non-dehydrogenation.

\section{Acknowledgements}

The authors would like to appreciate Dr. K. Yoneda, Director of LCD Division, SANYO Elec. Company, for his comments during the course of this study. The authors would like to thank Prof. T. Miki, Dept. Electrical \& Electronic Eng., Yamaguchi University, for his useful comments of ESR measurement. The thanks are also due to Assoc. Prof. S. Yamamoto, Dept. Advanced Materials Science \& Eng., Yamaguchi University, for his useful comments of sample preparation. This work was partly supported by the "Grant-in-Aid for Scientic Research from Ministry of Education, Science and Culture", and "OZAWA and YOSHIKAWA Memorial Electronics Research Foundation".

\section{References}

1) K. Hirano, N. Sotani, I. Hasegawa, T. Nohda, H. Abe and H. Hamada: Proc. SPIE AM-LCD Technology and Application, 1997, pp. 119-126.

2) H. Kuriyama, T. Nohda, S. Ishida, T. Kuwahara, S. Noguchi, S. Tsuda and S. Nakano: Jpn. J. Appl. Phys. 32 (1993) 6190.

3) Y. Morimoto, S. Nakanishi, N. Oda, T. Yamaji, H. Matsuda, H. Ogata and K. Yoneda: J. Electrochem. Soc. 141 (1994) 188.

4) N. Matsuo, A. Kinugasa, Y. Aya, T. Nouda, H. Hamada and T. Miyoshi, Trans. of IEICE C-II 80 (1997) 245.

5) H. Hamada, K. Hirano, N. Goda, H. Abe, I. Hasegawa, Y. Okita, S. Arioka and T. Niina: Electron. Lett. 30 (1994) 1719.

6) H. Hamada, A. Sasaki, Y. Okita and T. Niina: Jpn. J. Appl. Phys. 35 (1996) 680.

7) S. R. Stiffler, P. V. Evans and A. L. Greer: Acta metall. mater. 40 (1992) 1617.

8) H. Watanabe, H. Miki, S. Sugai, K. Kawasaki and T. Kioka: Jpn. J. Appl. Phys. 33 (1994) 4491.

9) C. V. Thompson: J. Appl. Phys. 58 (1985) 763.

10) Details will be presented in elsewhere. 